\title{
Analysis of the $5^{\prime}$-upstream regions of the human relaxin $\mathrm{H} 1$ and $\mathrm{H} 2$ genes and their chromosomal localization on chromosome 9 p $24 \cdot 1$ by radiation hybrid and breakpoint mapping
}

\section{J L Garibay-Tupas, K Csiszár ${ }^{1}$, M Fox $^{2}$, S Povey ${ }^{2}$ and G D Bryant-Greenwood}

Molecular Endocrinology Laboratory, Pacific Biomedical Research Center, University of Hawaii at Manoa, Honolulu, Hawaii, USA

${ }^{1}$ Laboratory of Matrix Pathobiology, Pacific Biomedical Research Center, University of Hawaii at Manoa, Honolulu, Hawaii, USA

${ }^{2}$ MRC Human Biochemical Genetics Unit, Galton Laboratory, University College, London, UK

(Requests for offprints should be addressed to J L Garibay-Tupas, Department of Anatomy and Reproductive Biology, 1960 East-West Road, Honolulu, Hawaii 96822, USA;

Email: jerme@pbrc.hawaii.edu)

\begin{abstract}
Relaxins are known endocrine and autocrine/ paracrine hormones that play a major role in reproduction. In the human there are two relaxin genes, $\mathrm{H} 1$ and $\mathrm{H} 2$ which share $90 \%$ sequence homology within their coding region. The biological and evolutionary significance of two highly homologous and biologically active human relaxins is unknown. In order to achieve a better understanding of the regulatory mechanisms involved in the differential expression of these two genes and to gain insight into their role(s) in the preterm premature rupture of the membranes, we have investigated the properties of their $5^{\prime}$-upstream regions and mapped them both by radiation hybrid and breakpoint mapping into the same chromosome $9 \mathrm{p} 24 \cdot 1$ locus. The $5^{\prime}$ ends of these relaxin genes could be divided into a proximal highly homologous segment and a distal non-homologous region. Within the proximal region are contained several
\end{abstract}

putative regulatory elements common to both genes, suggesting a similar regulatory mechanism. The clustering of the relaxin genes within the same chromosomal locus suggests that these genes may be under a common regulation. On the other hand, a distinct gene-specific regulation may also exist for the individual relaxin genes since cis elements specific to each gene were identified at their $5^{\prime}$ ends. Moreover, the observed divergence at the distal region of their $5^{\prime}$-upstream sequences may provide the structural features that act as gene-specific transcription regulators. Since the two genes are highly homologous in both their coding and flanking regions, the divergence at the distal region of their $5^{\prime}$ ends may be important in the regulation of these genes and in their involvement in the pathology of preterm birth.

Fournal of Molecular Endocrinology (1999) 23, 355-365

\section{INTRODUCTION}

Relaxin is a $6 \mathrm{kDa}$ polypeptide hormone and a member of the insulin superfamily. In the human there are two non-allelic genes for relaxin, termed $\mathrm{H} 1$ and $\mathrm{H} 2$ that encode two biologically active relaxin peptides (Crawford et al. 1984). Relaxin is best known as an endocrine hormone produced by the ovary and acting on the mammalian reproductive system to cause uterine quiescence and to remodel connective tissues, thereby facilitating the birth process (Bryant-Greenwood \& Schwabe 1994). The systemic relaxin acting in this way is the $\mathrm{H} 2$ form and the only relaxin produced by the human corpus luteum (Hudson et al. 1984). It has been shown, however, that relaxins are also autocrine/paracrine hormones in a number of other tissues such as prostate (Hansell et al. 1991), placenta (Sakbun et al. 
TABLE 1. PCR primers used for the promoter walking experiments

\section{Outer}

\section{3' Primer}

Walk 1

Relaxin $\mathrm{H} 1$

Relaxin H2

Walk 2

Relaxin $\mathrm{H} 2$

Walk 3

Relaxin $\mathrm{H} 2$

5'-Primer

\section{5'-ATAACATCGTCCTTCCATTTGG-3' \\ $5^{\prime}$-CTTCCTCCATCCATGAGTCC-3'}

5'-CTAATCTACATCTCTGGAGACTGG-3'

5'-TGGTGTGAATTTCAGCTCACTG-3'

(Adaptor 1: AP1): outer

5'-GTAATACGACTCACTATAGGGC-3'
Nested

5'-TTCTAGCAGGTGGAACAAGAACAG-3'

5'-GTAGTAAACAGACTCCTAGCAGGTGG-3'

5'-GATCCACACTGTTCTAGGTAATATG-3'

5'-CAGATTGAGAGTTGTCATGCAC-3'

(Adaptor 2: AP2): nested

5'-ACTATAGGGCACGCGTGGT-3'
1990), endometrium, decidua (Bryant-Greenwood et al. 1993) and mammary gland (Tashima et al. 1994). When relaxins are produced and act locally in this manner, both relaxin genes are expressed (Bryant-Greenwood \& Schwabe 1994). The reasons for the additional expression of the relaxin $\mathrm{H} 1$ and/or its suppression in the corpus luteum are not known.

An overexpression of the relaxins in the decidua and placenta has been shown to be associated with the preterm premature rupture of the membranes (Bogic et al. 1997), but it is not yet known whether one or both relaxins are upregulated in this condition. Relaxin overproduction in turn upregulates the expression of the matrix metalloproteinases (MMPs), which then increase the degradation of the extracellular matrix in this tissue, leading to tissue weakening, and premature rupture and preterm birth (Qin et al. 1997a,b).

There has been no in-depth study of the genetic etiology of preterm birth, although it has been shown that a previous history of preterm birth is a strong risk factor for another preterm delivery (Carr-Hill \& Hall 1985, Porter et al. 1997). Moreover, there are well-described racial differences in the incidence of preterm deliveries (Shiono \& Klebanoff 1986, Migone et al. 1991). A single study suggests the association of a rare allele of the tumor necrosis factor- $\alpha(\mathrm{TNF}-\alpha)$ gene arising from genetic polymorphism in the promoter region, with a 3.7-fold increased risk of African-Americans delivering preterm (Roberts et al. 1999). There have been no similar studies on the relaxin genes in the ethnic groups in which preterm delivery is markedly increased. Thus, the determination of the precise localization of the two human relaxin genes was undertaken in order to further understand the evolutionary significance of the two relaxins in the human, and to gain insight into the regulation of their expression in the pathology of the preterm premature rupture of the fetal membranes.

\section{MATERIALS AND METHODS}

\section{Isolation of the 5 -flanking regions of the relaxin $\mathrm{H} 1$ and $\mathrm{H} 2$ genes}

Genomic clones containing the 5 '-flanking regions of the human relaxin $\mathrm{H} 1$ and $\mathrm{H} 2$ genes were isolated using a PCR-based chromosome walking method based on the Promoter Walking Kit (Clontech, Palo Alto, CA, USA). The initial outer and nested 3 '-gene specific primers were designed for relaxins $\mathrm{H} 1$ and $\mathrm{H} 2$ based on their published sequences (Gunnersen et al. 1995). Subsequent primers were then designed from the cloned fragments as shown in Table 1. The PCR amplification was performed as per the manufacturer's instructions using seven cycles of denaturation/annealing at $94{ }^{\circ} \mathrm{C}, 2 \mathrm{~s} ; 70{ }^{\circ} \mathrm{C}$, $3 \mathrm{~min}$, followed by 37 cycles of denaturation/ annealing/extension at $94{ }^{\circ} \mathrm{C}, 2 \mathrm{~s} ; 65^{\circ} \mathrm{C}, 3 \mathrm{~min}$, and a final extension at $65^{\circ} \mathrm{C}$ for 4 min for the primary $\mathrm{PCR}$ reaction. The PCR products generated were then used as templates for the secondary PCR which was carried out under the following conditions: five cycles at $94{ }^{\circ} \mathrm{C}, 2 \mathrm{~s}, 70{ }^{\circ} \mathrm{C}, 3 \mathrm{~min}$; then 20 cycles at $94^{\circ} \mathrm{C}, 2 \mathrm{~s}, 65^{\circ} \mathrm{C}, 3 \mathrm{~min}$; and a final extension at $65^{\circ} \mathrm{C}$ for $4 \mathrm{~min}$. The amplified genomic DNAs were purified after agarose gel electrophoresis and subcloned into the TA cloning vector pCR2.1 (Invitrogen, San Diego, CA, USA). Clones were sequenced in both directions by the Biotechnology Molecular Biology Instrumentation Facility at the University of Hawaii, using the doublestranded dideoxychain termination method (Sanger et al. 1977). The $5^{\prime}$ end of relaxin $\mathrm{H} 2$ isolated from the promoter library was derived from three overlapping clones, therefore, a single nonoverlapping clone was subsequently isolated by genomic PCR using undigested placental genomic DNA obtained from Clontech. A genomic clone was similarly isolated for the relaxin H1 using the same placental genomic DNA, and its identity confirmed. 
TABle 2. PCR primers used for genomic PCR amplification of the 5'-upstream regions of relaxin $\mathrm{H} 1$ and $\mathrm{H} 2$ genes

5' Primer

Relaxin

H1

$\mathrm{H} 2$
5'-TCTTAGCCTAGTTAAGGGTTTGTCAG-3'

5' ${ }^{\prime}$ 'TTCCTGTGGTAAACCATCTAG-3'
3' Primer

5'-TTCTAGCAGGTGGAACAAGAACAG-3'

5'-GATCCACACTGTTCTAGGTAATATG-3'
The primers used for the genomic PCR amplification are shown in Table 2, this was performed with Clontech's Advantage Genomic PCR kit, using the following conditions: initial denaturation at $95{ }^{\circ} \mathrm{C}, 1 \mathrm{~min}$; followed by 25 cycles of $95^{\circ} \mathrm{C}, 10 \mathrm{~s}$; $55^{\circ} \mathrm{C}, 30 \mathrm{~s} ; 65^{\circ} \mathrm{C}, 3 \mathrm{~min}$ and a final extension of $70{ }^{\circ} \mathrm{C}$ for $2 \mathrm{~min}$. The two DNAs were sequenced in both directions in order to confirm the identities of the genomic clones obtained.

\section{Primer extension analysis of transcription initiation}

Poly (A) ${ }^{+}$RNAs were prepared from the prostate gland of a young male obtained from the National Disease Research Interchange (Philadelphia), and from the prostate adenocarcinoma cell line LNCaP. FGC. The prostate was selected because it has been shown to express both relaxin $\mathrm{H} 1$ and $\mathrm{H} 2$ genes at a relatively high level. The $\mathrm{LNCaP}$ cells were grown to confluency in RPMI 1640 medium containing $10 \%$ fetal calf serum (Gibco BRL, Grand Island, $\mathrm{NY}, \mathrm{USA})$, at $37^{\circ} \mathrm{C}$ and $5 \% \mathrm{CO}_{2}$. The poly $(\mathrm{A})^{+}$ RNAs were extracted using Invitrogen's (Carlsbad, CA, USA) fast track mRNA kit. The two sets of oligonucleotide primers for each relaxin gene used were the outer and nested primers for promoter walk 1 shown in Table 1 . These primers $(100 \mu \mathrm{M})$ were 5 '-end labeled with $\gamma^{32} \mathrm{P}$-dATP (NEN Research Products, Boston, MA, USA) using T4 polynucleotide kinase (Gibco BRL) then purified by passing the labeled products in a Sephadex G-25 column. Five picomoles of the labeled primers were annealed to $5 \mu \mathrm{g}$ poly $(\mathrm{A})^{+}$RNA using $\mathrm{MuLV}$ reverse transcriptase and reagents from $\mathrm{PE}$ Applied Biosystems (Foster City, CA, USA), then incubated at $23{ }^{\circ} \mathrm{C}$ for $10 \mathrm{~min}, 42{ }^{\circ} \mathrm{C}$ for $15 \mathrm{~min}$ and $94{ }^{\circ} \mathrm{C}$ for $5 \mathrm{~min}$. The reverse transcribed cDNAs were analyzed by electrophoresis using $8 \%$ polyacrylamide gel containing $6 \mathrm{M}$ urea followed by autoradiography of the fixed/dried gel. Plasmid DNAs encoding the $5^{\prime}$ ends of the two relaxin genes were sequenced using the nested primers (Table 1) with reagents from Gibco BRL's dsDNA cycle sequencing system and following the manufacturer's instructions. These sequence ladders were used as size markers for the primer extension products.

\section{Radiation hybrid mapping}

To map the precise chromosomal localization of the relaxin $\mathrm{H} 1$ and $\mathrm{H} 2$ genes by radiation hybrid mapping, gene-specific primers were made to a specific sequence of each of the relaxins' 5 ' ends with low $(37 \%)$ homology (Fig. 1). These genespecific primers were used for the PCR-based screening of the GeneBridge 4 radiation hybrid panel (Walter et al. 1994, Gyapay et al. 1996), obtained from Research Genetics (Hunstville, AL, USA). A $579 \mathrm{bp}$ segment of genomic DNA was amplified with the relaxin $\mathrm{H} 1$ primers (forward: 5'-TGGAGGTTGCAGTGAGCTGAGCTTG-3' and reverse: 5'-GTGCACATTCCCGGATAGA CCATTTG- $3^{\prime}$ ) while those for relaxin $\mathrm{H} 2$ (forward: 5'-TCAAGTGCCACTAAAGTATGCC-3' and reverse: 5'-TGAAGCAGACATAGAAAGG GAG-3') amplified a 419 bp genomic DNA. Polymerase chain reactions were performed as described by Szabo et al. (1997), with minor modifications. The reaction volume $(15 \mu \mathrm{l})$ contained $40 \mathrm{mM}$ Tricine- $\mathrm{KOH}\left(\mathrm{pH} 9 \cdot 2\right.$ at $\left.25^{\circ} \mathrm{C}\right)$, $15 \mathrm{mM}$ KOAc, $3 \cdot 5 \mathrm{mM} \mathrm{Mg}(\mathrm{OAc})_{2}, 75 \mu \mathrm{g} / \mathrm{ml}$ bovine serum albumin, $200 \mu \mathrm{M}$ each dNTP, $1 \mu \mathrm{M}$ primers, $37 \cdot 5 \mathrm{ng}$ hybrid DNA and $0 \cdot 3 \mu \mathrm{l}$ of $50 \times$ advantage KlenTaq polymerase mix (Clontech). For amplification of the relaxin $\mathrm{H} 1 \mathrm{DNA}$, the initial denaturation was carried out at $95^{\circ} \mathrm{C}$ for 1 min followed by 30 cycles of $95^{\circ} \mathrm{C}, 10 \mathrm{~s} ; 64^{\circ} \mathrm{C}, 30 \mathrm{~s} ; 72^{\circ} \mathrm{C}, 1 \mathrm{~min}$; and a final extension of $72{ }^{\circ} \mathrm{C}$ for $2 \mathrm{~min}$. For relaxin $\mathrm{H} 2$ these were: initial denaturation at $95^{\circ} \mathrm{C}$ for $1 \mathrm{~min}$ followed by 30 cycles of $95^{\circ} \mathrm{C}, 10 \mathrm{~s} ; 55^{\circ} \mathrm{C}, 30 \mathrm{~s}$; $65{ }^{\circ} \mathrm{C}, 1 \mathrm{~min}$; and a final extension of $70^{\circ} \mathrm{C}$ for $2 \mathrm{~min}$. Two positive controls were used and these were genomic DNA from two human cell lines: cervical carcinoma HeLa cells and human lung fibroblasts (HFLs). The negative control was genomic DNA from hamster. All three controls were included in all the experiments which were always carried out in triplicate. The PCR products were separated in single four-tiered $1.5 \%$ agarose gels in $1 \times$ Tris-acetate (TAE) buffer for $90 \mathrm{~min}$ at $100 \mathrm{~V}$ and visualized by ethidium bromide staining. Photographs of gel images were taken and used to score the presence of PCR products of the expected size. The 93 radiation hybrid panels were scored following the instructions 
A

-2844 CACAAGAATCGCTTGAACTCATGAG HGGAGGTTGCAGTGAGCTGAGCTTGT SCCACTGCACTCCAGCCTCGATGATGGÄTGAGACTCTGTCTCAAAAA RLN1

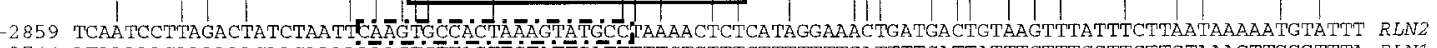
2744 ATAAAAACAAAAAACAACAAAA ÄA ATCTTAGTT GTATTGATTTTTCTGTTTCTTTTTTTGA TTTTCATTATTTCTTTCCTTCTTCTAAAGTJGGGTTTA RLN1

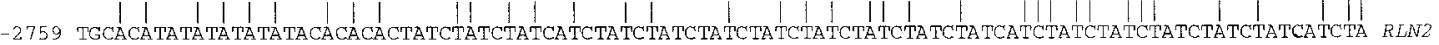
2644 GTTTTCATCTTTTTCTAGTTCCTTGAGCTGTAATGTTAAGCTA TTTATTTGGGATCTTTTTCTTCTTTTTTAATGTAGGCATTPATTGTTATTACATAAAC RLN1

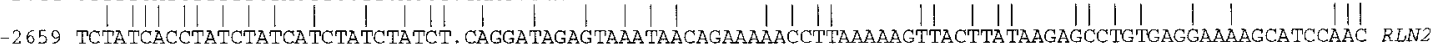
-2544 TTCCCTTTTAAAACTGCTTTTGCTGCATCCCATAGGTCTTGGTATATTGTGTTTCCAATGTTATTTGTCTCAAGATATTCTGTAATTTCCTTTTTTTTGT RLN1

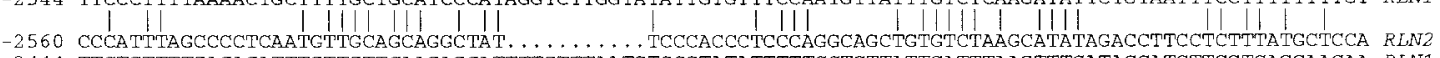
-2444 TTCTGTTTTGACACATTTGTTGTTCAAGAGCA TTTTGTTTAA TGTCCGTATATTTTTCCTGTIATTGATTTAAGTTTCATACCATCTTGGTCAGGAACAA RLN1

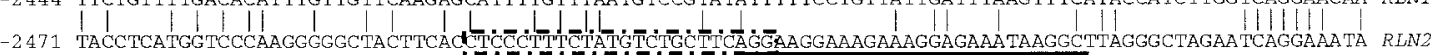
-2344 TATTIGATGTGATTTTGATCTTAAATTTATTA TGA CTTGTTTGTGCC CTA OCAAATGGTCTATCCGGGAATGTGCAG FAGAGAAAAATGCGGATTCTGC RLNI

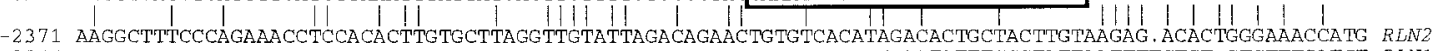
-2244 TGTTGGATAAAATGTTCTGCATGTATCTGTTACGGCCATTTTGTCTACAGTGCAATTCAGTTTCAATA TTTCCGTA TT'AATTTTTCTGT . GTCI"ITGATCT RLN1

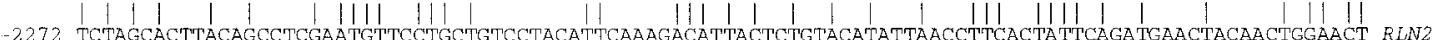
-2145 GTATGTTGTTGAGAGTGGAGTGTTAAAGTCCTCTCTCA TUACTGTAGAAGAATCCAGTAGACATGGGTTGGAACCCCACCTCCAGCATGTIGACAGCTGTA RLN1 -2172 GGatctagGatataggGaAatgaAgGa. |

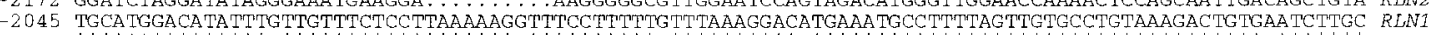
-2082 TGCATGGACATA TTTA TTGTTTCTCCTTAAAAAGATTTCCTTTTTA TTTAAAGGACTTGAAATGCCTTTTAGTTGTGCCTGTAAAGACTGTGGATCTTGC RLN2

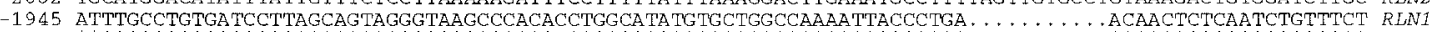

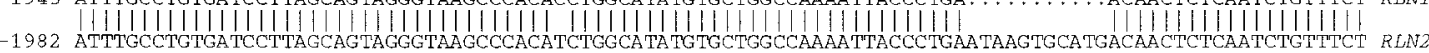

1856 TCTTTCTGTAAAATGGAAAAGTGGCCACTGTACTGGACAGTTTTAAGGACTCTGTAAAACCACGTAGGCAACATAAAATTTCAAAACA TCCCTGGACACT RLN 1

- 1882 TCTTTCTGTAAAATGGGAAAGCGGGCATTGTACTGGACAGTTTAAGGACTCTATAAAACATGTAGGCAACATAAAAAATCAAAATATCCCTGGACACT RLN2

1756 TTGGGAGGCCGAGGCAGGTGGA TCACCTGAGGTCAGGAGTTCGAGACCAGCCTATCCAACATGGTGAAACCCAGTCTCCACCAAAAATACAAAAATTAGC RLN1

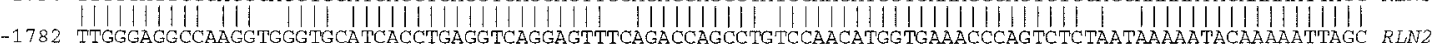

- 1782 TGGGAGGCCAAGGTGGGTGCATCACCTGAGGTCAGGAGTTTCAGACCAGCCTGTCCAACATGGTGAAACCCAGTCTCTAATAAAAATACAAAAATTAGC RLN2

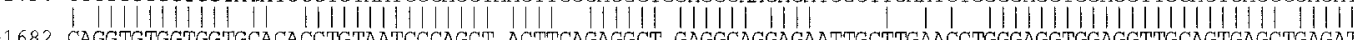

-1682 CAGGTGTGGTGGTGCACACCTGTAATCCCAGCT, ACTTCAGAGGCT . GAGGCAGGAGAATTGCTTGAACCTGGGAGGTGGAGGT'TGCAGTGAGCTGAGAT RLN2

-1556 TGCACCATTGCACTCCAGCCTGGGTGACAAGAGCCAAA TTCTGTCTCAAAAAAA TCACCCAAAAACAAACAA ..........AAAACTCTGGAAATTTACAT RLN1

- 1584 CACACCATTGCACTCCAGCCT.GGCGACAAGAGCCAAATTCTGTTTAAAAAAAAAAAACAAACAAAAAACAAAAACAAAGAAATCCCTGGAATTTACAT RLN2

-1464 TTTTAATGAGCAATTAATTTGGAGTACAGCCTAGCACGTGGATTGTTTTTACAAGGAACTGTTAACCCACGAAAATATTTTCAAACCTCAGTTTTGAGGG RLN1

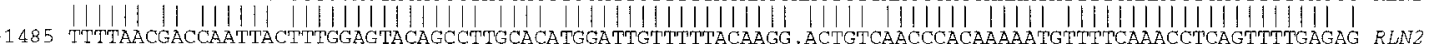

-1364 GCCTTTCTCAAACTGTGTGTTTTAGTGAAAATCCATTTAAAATCATTAATTGCCTCTAACCATCTCATAGCTTTGGTCA. GGTATTTTTTGAAGAATTAC RLN1

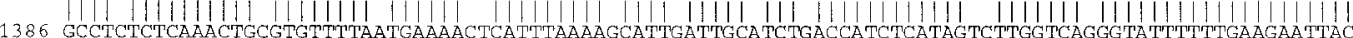

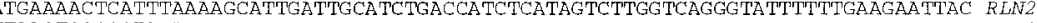

- 265 ACATGCTTGGCATTTGACCAATGTTAAGTGGCCCTACTGAAATCACCAGATI

-1286 ACATTGCTTGGCATTTGACCAATGCTAAGTGGGCCTACTGATATCACCAGCAATCTAGAAA'TIAGAGTTATTTGATTCCA TAGTTATGTTITGTAACTAAG RLN2

1166 AGATTGTTATTA TTTTATTTTCAAAGCTACCATAACGTCCTGCATGTCTCCAGTTTA TCTGATGGAGCTGAACTAATCTGAGTATATTA TGAACACAAGCA RLN1

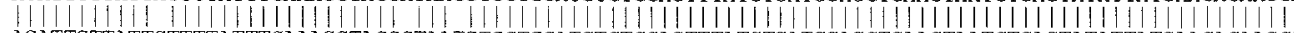

1186 AGATTGTTATTCTTTTA TTTCAAAGCTACCCTAATGTCCTGCATGTCTCCAGTTTATCTGATGGAGCTGAACTAATCTGAGTATATIATGAACACAAGCA RLN2

- 1066 AGATTGTUTATTATTITATTTCAAAGCTACCATAACGTCCTGCATGTCTCCAGTTTATCTGATGGAGCTGAACTAATCTGAGTATATTATGAACACAAGCA RLN1

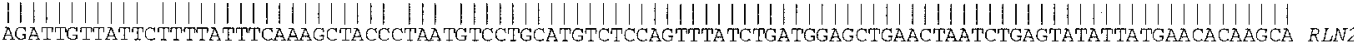

-966 AGTAAGTTATTTTTAAAAATGAACCTATTTGTACTAAAAA TTTACAGGTAGAAGGGTCGTCTACTAACCA TA TTATCTAGAACTGTGTGGATCTTTAAAA RLN1 |||||||||||||||||||||||||||||||||||||||||||||||||||||||||||||||||||||||||||||||||||||||||||||| $\mid$

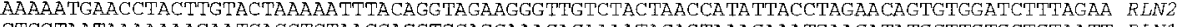

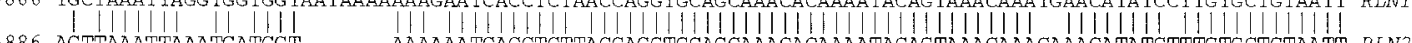
-886 AGTTAAATTAAATGATGGT........... AAAAAATCACCTCT TACCAGGTGCAGCAAACA CAAAATACAGTAAACAAACAAACA TATCTTTGTGCTGTAATT RLN2

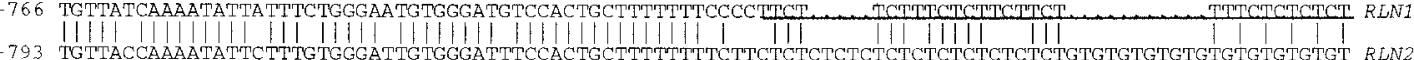

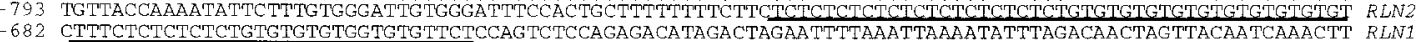

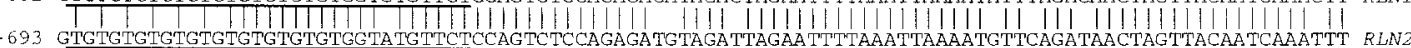
582 CTCCCACAGGAGTGGAAGGAAAGTCCAA TGGA GAAATTGTPTPTGTAAATTAAAGACATTACTGCACAAGCCTAAAATGATGT"TACTGGGGA'T"I"T"TARTCT RLNI

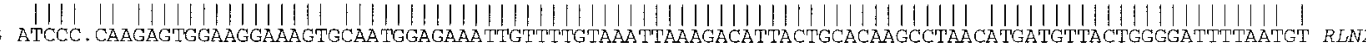

-482 TTTTACCTGGATTCAGA TTAAAAGTCATCAGTTTTTCCCTC TCATCAACAATTTA TTCA TTPCA TCCA . . . . . . TTATATTTTTATGGATTGA TA TGCCC RLN

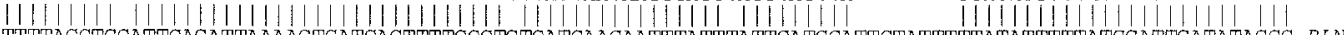

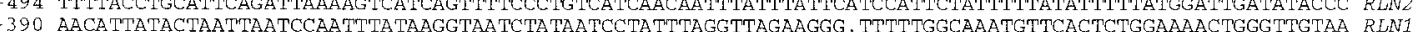

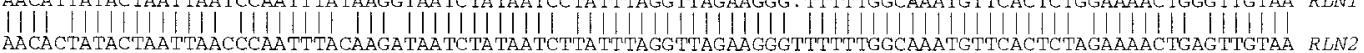
-394 AACACTATACTAATTAACCCAATTTACAAGATAATCTA TAATCTTATTTAGGTTAGAAGGGTTTTTTGGCAAATGTTCACTCTAGAAAACTGAGTTGTAA RLN2

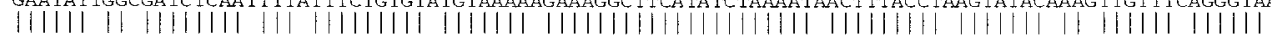

-294 GAATATGGGTGA TCTCAAATTIGTTTCTGTGTGTGTAAAAGGAAAGGCTTCATATCTAAAATGACTTTACCTCAGTATACTAAATTGTTTGAGGGTAATG RLN2 - 91 AAAGAGCGAAAAACAAAACTGTAAAAGGGCCAAGGACAGAGGAATGGGCAAATGAAGGAAGGGCGGAGAGGCAGAACAAGAGCTGAAGGAGAAAATTCTG RLN1

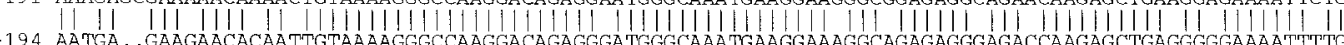

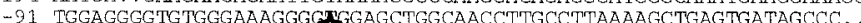

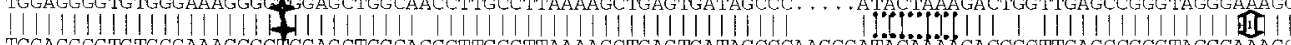

5 AGCCTAAAGCCCGGGACAGGCACACAGGCCCAGGTGTG TA GGCCACAGCAGCCGCAGTCCTGAAAGGCTGCAACACCCAGACCTCCAGGAGAGACCAGGC RIN1

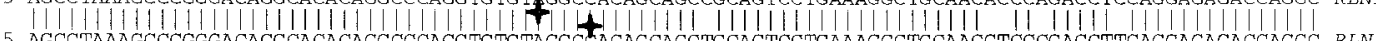
5 AGCCIAAAGCCCGGGACAGGCACACAGGCCCAGGTGTGTAGGCCACAGCAGCTGCAGTCCTGAAAGGCTGCAACGTCCCGACCTTCAGGAGAGACCAGGC RLN2
105 CCAGG̈TGECTCGCOTGTTCTTGTTCCACCTGCTAGAATTCTGTITACTACTGAACCAATTTTCCAGAGCAGTCGCGGCCAAATGAAGGACGA TGTTAT RLN1

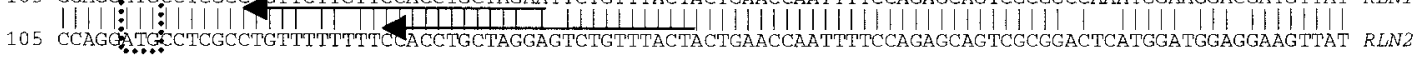




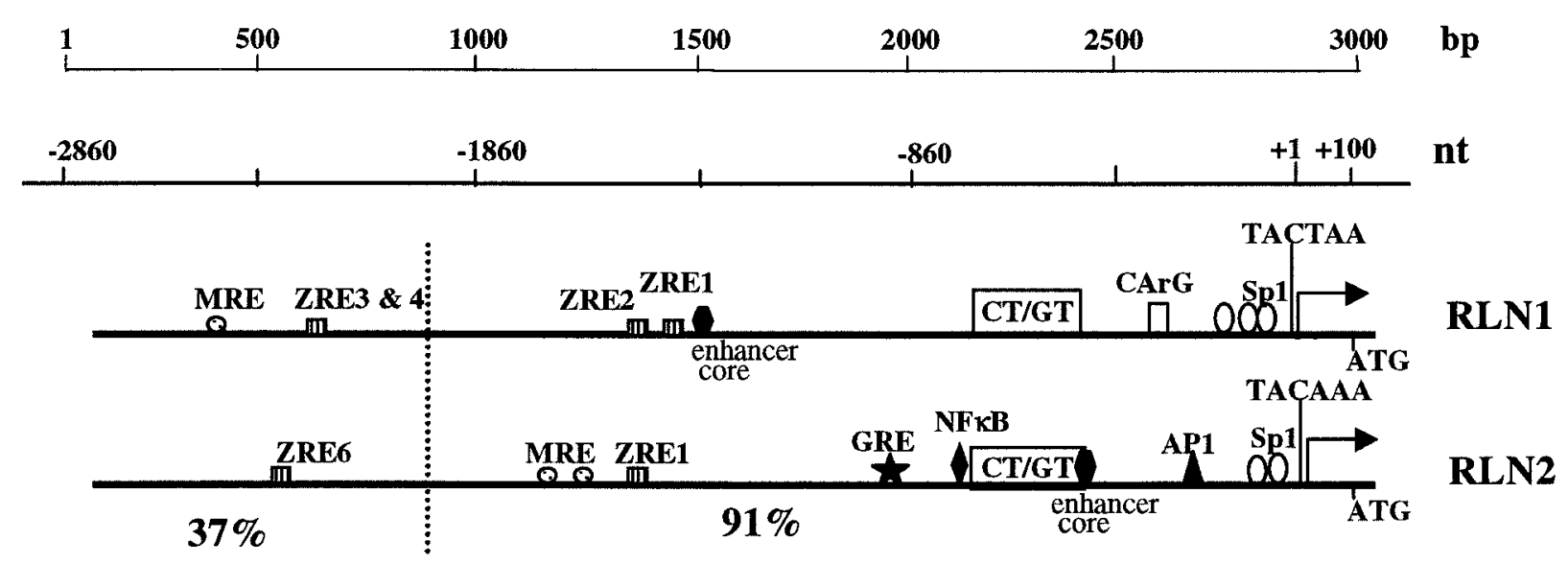

FIGURE 1. (A) The $5^{\prime}$-upstream regions of the human relaxin $\mathrm{H} 1$ and $\mathrm{H} 2$ genes. The nucleotide sequences of the relaxin H1 (GenBank accession no. AF104934) and H2 (GenBank accession no. AF104935) 5'-upstream regions were compared using the GCG-GAP program. The numbering of the nucleotide residues is relative to the position of the major transcription start site which was designated as (+1). To obtain maximal alignment, gaps were introduced and shown as dots while the vertical bars between sequences show identical nucleotides. The proximal region of these $5^{\prime}-$ upstream sequences show 91\% homology while the distal region has only $37 \%$ homology. The gene-specific primers used for the radiation hybrid mapping were designed from the distal region and are enclosed by solid rectangles for the relaxin $\mathrm{H} 1$ primers or dashed/dotted rectangles for the relaxin $\mathrm{H} 2$ primers. The CT/GT microsatellite repeats are underlined, the putative TATA boxes are dotted, the ATG translation initiation codon is enclosed in dotted rectangle. Three transcription starts sites were detected through primer extension, the minor upstream (T at $-71 \mathrm{nt}$ for RLN1 or -76 for RLN2) and downstream (A at +44 nt for RLN1; C at +48 nt for RLN2) sites are indicated by four-pointed stars, while the major transcription initiation sites (A for both relaxin genes) are indicated by double-sided arrowheads and +1 . The nested primers used for the primer extension and for the sequencing ladders are underlined (RLN1) or overlined (RLN2) with arrows showing the direction of cDNA synthesis. (B) A schematic comparison of the relaxin H1 and H2 5'-upstream regions indicate the positions of putative transcription regulatory elements. The major transcription start site (arrow) was used as the reference point for the numbering of nucleotides. Non-canonical TATA boxes for RLN1 and RLN2 and the various putative cis elements are indicated. Most of these elements are concentrated within the proximal region. A dashed vertical line separates the proximal homologous region from the distal non-homologous portion. A nucleotide scale above the diagram shows the length of these regions.

available at the website: (http://www-genome.wi. mit.edu/ftp/distribution/human_STS_releases/oct96. INTRO.html\#RH) and the results were submitted for linkage analysis to a server at the Whitehead Institute/MIT Center for Genome Research (http:// www-genome.wi.mit.edu/cgi-bin/contig.rhmapper.pl). Linkage analysis was carried out at logarithm of the odds (LOD) scores 15, 17, 19 and 21 using RHMAPPER (Stein et al. 1995).

\section{Isolation of a P1 clone}

Using a PCR-based strategy the P1 library was screened by Genome Systems Inc. (St Louis, MO, USA), with the same relaxin $\mathrm{H} 2$ gene-specific primers used for the radiation hybrid mapping. A single positive clone P1\# 16225 was isolated. Before extraction of the P1, plasmid DNA clone 16225 , which was maintained in $E$. coli strain NS3529, was transferred to strain NS3516 by transduction in order to increase the yield of plasmid DNA (Sternberg et al. 1994). The transformed $E$. coli cells were then grown to stationary phase overnight at $37{ }^{\circ} \mathrm{C}$ in $\mathrm{LB}$ medium containing $25 \mu \mathrm{g} / \mathrm{ml}$ kanamycin and $1 \mathrm{mM}$ isopropyl $\beta$-D-thiogalactopyranoside (IPTG), which induces the lytic replicon to amplify the plasmid copy number (Sternberg et al. 1994). The P1 plasmid DNA was isolated by a modified alkaline lysis procedure, extracted with phenol/chloroform $(1: 1 \mathrm{v} / \mathrm{v})$, precipitated in isopropanol and washed in $70 \%$ ethanol (Sternberg et al. 1994). The size 
of the P1 clone was estimated by restriction digestion of the plasmid DNA with several endonucleases, following the methods of MacLaren \& Clarke (1996). The DNA fragments were analyzed using a Field Inversion Gel Electrophoresis (FIGE) Mapper system (BioRad, Hercules, CA, USA), blotted onto nylon membranes (MSI, Westborough, MA, USA), then hybridized with ${ }^{32} \mathrm{P}$-labeled probes specific to either side of the insert cloning site of the vector (MacLaren \& Clarke 1996). To verify that both genes were cloned into the P1 plasmid the blots were deprobed then reprobed with ${ }^{32} \mathrm{P}$-labeled fulllength $(558 \mathrm{bp})$ relaxin $\mathrm{H} 2 \mathrm{cDNA}$ which recognizes both relaxin genes. This was verified further by PCR amplification of the $\mathrm{H} 1$ and $\mathrm{H} 2$ DNA fragments, using the same gene-specific primers and conditions as described in the radiation hybrid mapping section.

\section{Breakpoint mapping and fluorescent in situ hybridization analysis}

Fluorescent in situ hybridization (FISH) was carried out on metaphase chromosome spreads obtained from normal male lymphocyte cultures which served as control and from Epstein-Barr virus transformed lymphoblastoid lines obtained from individuals with balanced $9 p$ translocations. There were three lines forming the panel: D1151 with karyotype 46,XY, t(7;9)(q34·1;p24·1); HW1069 with karyotype 46,XX, t(9;11)(p24·1;q22) and D118 with karyotype 46,XX, t(9;10) (p22.3; $111 \cdot 2)$ as described by M T Rebello (unpublished observations). Metaphase chromosome spreads were prepared using standard cytogenetic methods. P1 plasmid DNA containing the relaxin $\mathrm{H} 1$ and $\mathrm{H} 2$ genes was biotin-labeled by nick translation and hybridized to metaphase chromosomes. The signal was detected by fluorescein isothiocyanate (FITC) using techniques described in Gillett et al. (1993). Chromosomes were counterstained with 4',6-diamidino-2-phenylindole (DAPI), examined using a Zeiss Axioskop fluorescent microscope, and images were captured by cooled charge-coupled device (Photometrics) using Smartcapture software (Digital Scientific, Ltd, Essex, UK).

\section{RESULTS}

\section{Isolation and analysis of the relaxin $\mathrm{H} 1$ and H2 5'-flanking regions}

A $3.0 \mathrm{~kb}$ relaxin $\mathrm{H} 1$ genomic DNA was isolated after a single round of PCR using the Promoter

Fournal of Molecular Endocrinology (1999) 23, 355-365
Walking kit, and was shown to contain the 5 -upstream region. On the other hand, the $2.9 \mathrm{~kb}$ $5^{\prime}$-upstream region for relaxin $\mathrm{H} 2$ was obtained after a series of three promoter walks. A comparison of the two $5^{\prime}$-end sequences (Fig. 1A) showed an overall homology of 76\% (GCG-GAP program, University of Wisconsin), however, two distinct regions with differing sequence homologies were observed. The proximal region spanning $\sim 2.0 \mathrm{~kb}$ immediately upstream of the ATG translation initiation codon showed a $91 \%$ homology between the two genes, while the $\sim 1.0 \mathrm{~kb}$ distal segment showed only $37 \%$ homology (Fig. 1B). To confirm that both relaxin 5 '-end segments were indeed present in the human genome, genomic PCR was performed using undigested placental DNA to amplify the $\sim 3.0 \mathrm{~kb}$ fragments. These genomic DNAs were sequenced and were found to be identical with those obtained through the promoter walking strategy, confirming that the observed drop in the sequence homology at the distal region of both genes was correct.

Analysis of the $5^{\prime}$-upstream regions of relaxin $\mathrm{H} 1$ and $\mathrm{H} 2$ showed that a typical TATA box is lacking from both genes, instead relaxin $\mathrm{H} 1$ has the variant TACTAA, while in relaxin $\mathrm{H} 2$ the TACAA which is found in the same position may act as a TATA box (Fig. 1A). A schematic comparison of the relaxin $\mathrm{H} 1$ and $\mathrm{H}_{2} 5^{\prime}$ ends and the presence of several putative regulatory elements are shown in Fig. 1B. Three Sp1 binding sites were identified in relaxin $\mathrm{H} 1$ in close proximity to the TACTAA sequence and corresponding two Sp1 binding sites were observed in the relaxin $\mathrm{H} 25^{\prime}$ end. Both sequences showed long stretches of CT-GT repeats within -750 to -650 nucleotides. Although the CT-GT repeats appear in the same region of both genes, the sequences are not identical and shared very limited similarities. Both genes have putative mineralocorticoid (MRE) and zinc responsive elements (ZRE), although they were found at different positions. A unique feature for the relaxin H1 $5^{\prime}$-end is the GC-rich CArG box, while sites for AP1 and NFkB binding and a glucocorticoid response element (GRE) were found only in the $5^{\prime}$ end of relaxin $\mathrm{H} 2$.

Through primer extension analysis using mRNA from the prostate and $\mathrm{LNCaP}$ cells, the transcription initiation sites were determined for the relaxin $\mathrm{H} 1$ and $\mathrm{H} 2$ genes. Each gene has three transcription initiation sites found to be in similar locations within their $5^{\prime}$-upstream regions (Fig. 1A). The major transcription initiation site in both relaxin $\mathrm{H} 1$ and $\mathrm{H} 2$ genes was found to be in a similar position as the transcription initiation site for the porcine relaxin gene (Haley et al. 1987). Thus, the size of the human relaxin $\mathrm{H} 1$ and $\mathrm{H} 25^{\prime}$-untranslated 
region of $\sim 109$ nucleotides corresponds to the reported size of $\sim 106$ nucleotides for the porcine relaxin gene (Haley et al. 1987).

\section{Chromosomal localization by radiation hybrid mapping}

The presence of a region with marked sequence difference (37\% homology) between the two relaxin $5^{\prime}$-upstream regions was useful in designing gene-specific primers which allowed the separate chromosomal mapping of each relaxin gene. Initial determination of the chromosomal localization of the relaxin genes was done by radiation hybrid mapping using the GeneBridge 4 panel. Triplicate mapping experiments were performed for both genes and the results were analyzed after agarose gel electrophoresis. The scoring and retention pattern for both genes in all the experiments were identical at all the LOD scores used and comparable with the sequence-tagged site (STS) marker WI-5527, positioned at $30 \cdot 1$ centirays (cR) from the telomeric end of chromosome 9. The distance between WI-5527 and the two relaxin genes was $0 \cdot 0 \mathrm{cR}$, thus both relaxin genes are clustered in the same locus as this STS marker which lies on the p $24 \cdot 1$ interval of the chromosome 9 short arm (Whitehead Institute map). The two relaxin genes were also located $4.1 \mathrm{cR}$ or 1.35 megabases $(\mathrm{Mb})$ telomeric of STS marker FB2G7 and $5.9 \mathrm{cR}$ or $1.59 \mathrm{Mb}$ centromeric of STS marker D9S286, which covers approximately $8.1 \mathrm{Mb}$ (Fig. 2). In comparison with the genetic map, this position lies within the $9-15 \mathrm{cM}$ (centimorgan) interval (Fig. 2).

\section{Breakpoint mapping by FISH}

To confirm the radiation hybrid mapping results, breakpoint mapping by FISH was carried out using a P1 clone containing both relaxin $\mathrm{H} 1$ and $\mathrm{H} 2$ genes, as a probe. This $\mathrm{P} 1$ clone has a genomic DNA insert of approximately $80 \mathrm{~kb}$ estimated by restriction mapping and Southern blotting, large enough to contain both full-length relaxin genes, each estimated to have a size of approximately 7-9 kb (Hudson et al. 1983). The presence of the relaxin $\mathrm{H} 1$ and $\mathrm{H} 2$ genes in the $\mathrm{P} 1$ clone was confirmed through PCR amplification and Southern blotting using a full-length $(558 \mathrm{bp})$ relaxin $\mathrm{H} 2$ cDNA as a probe (data not shown).

FISH was carried out on metaphase chromosomes from normal male lymphocyte cultures and from Epstein-Barr virus transformed lymphoblastoid lines obtained from individuals with constitutional $9 p$ translocations. The control metaphase chromosomes showed intense signals at the

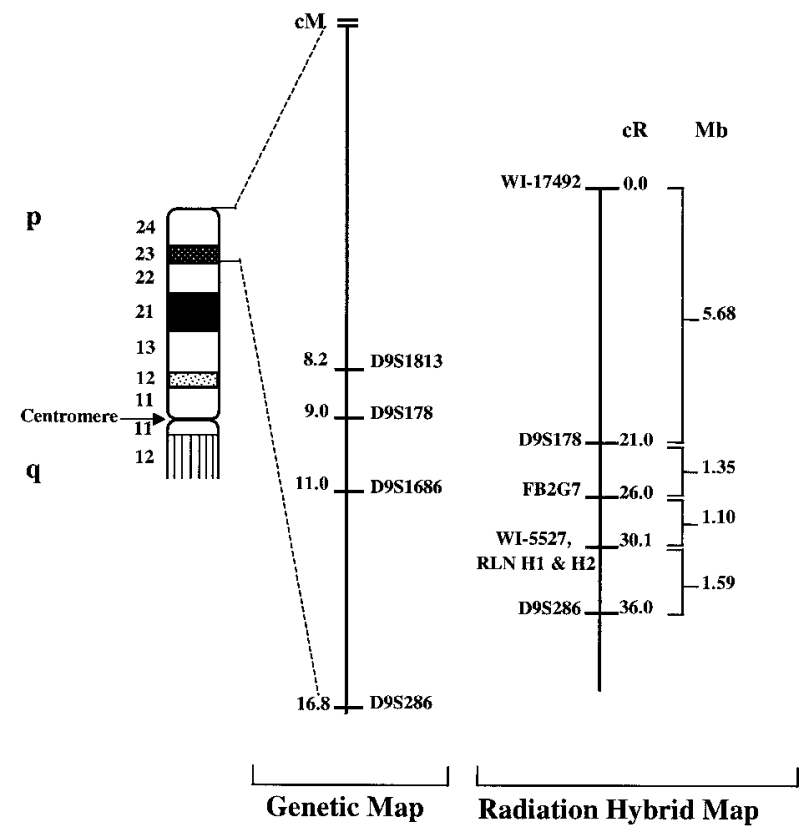

FIGURE 2. Radiation hybrid and genetic maps for the human relaxin $\mathrm{H} 1$ and $\mathrm{H} 2$ genes. The chromosomal regions are shown as intersecting lines. The distances between STS markers are indicated in centimorgans (cM) on the genetic map and centirays (cR) on the radiation hybrid map. The overall size of the genetic map based on the sex average is $158 \mathrm{cM}$ (GenLink http://www.genlink.wustl.edu). A diagram of chromosome 9 short arm is shown on the left side to indicate the localization of the markers and the relaxin genes within this chromosome. For this particular radiation hybrid map, the distances between STS markers given in megabases $(\mathrm{Mb})$ were based on the estimate of $3 \cdot 7 \mathrm{cR} / \mathrm{Mb}$ (Walter et al. 1994). The first marker WI-17492 positioned at $0 \mathrm{cR}$ is telomeric and the last marker D9S286 at $36 \mathrm{cR}$ is centromeric.

telomeric end of the short arm of chromosome (chr) 9 indicated by arrows in Fig. $3 a$. Finer mapping was achieved using three transformed cell lines bearing various translocation breakpoints. Beginning at the most distal breakpoint on chromosome 9, the cell line D1151 with a karyotype 46,XY, t(7;9)(q34.1; $\mathrm{p} 24 \cdot 1)$ gave strong signals nearly at the end of the short arm of the normal (N) chr 9 and its translocation derivative (der), but not in either normal chr 7 or its derivative (Fig. $3 b$ ). Using the HW1069 cell line which has a balanced translocation between chr 9 short arm and chr 11 long arm and a karyotype of 46,XX, t(9;11)(p24·1; 22$)$, fluorescent signals were observed in both the normal and chr 9 derivative but not in N11 or in der 11 (Fig. 3c). In the cell line D118 which contains the most proximal balanced translocation with a 

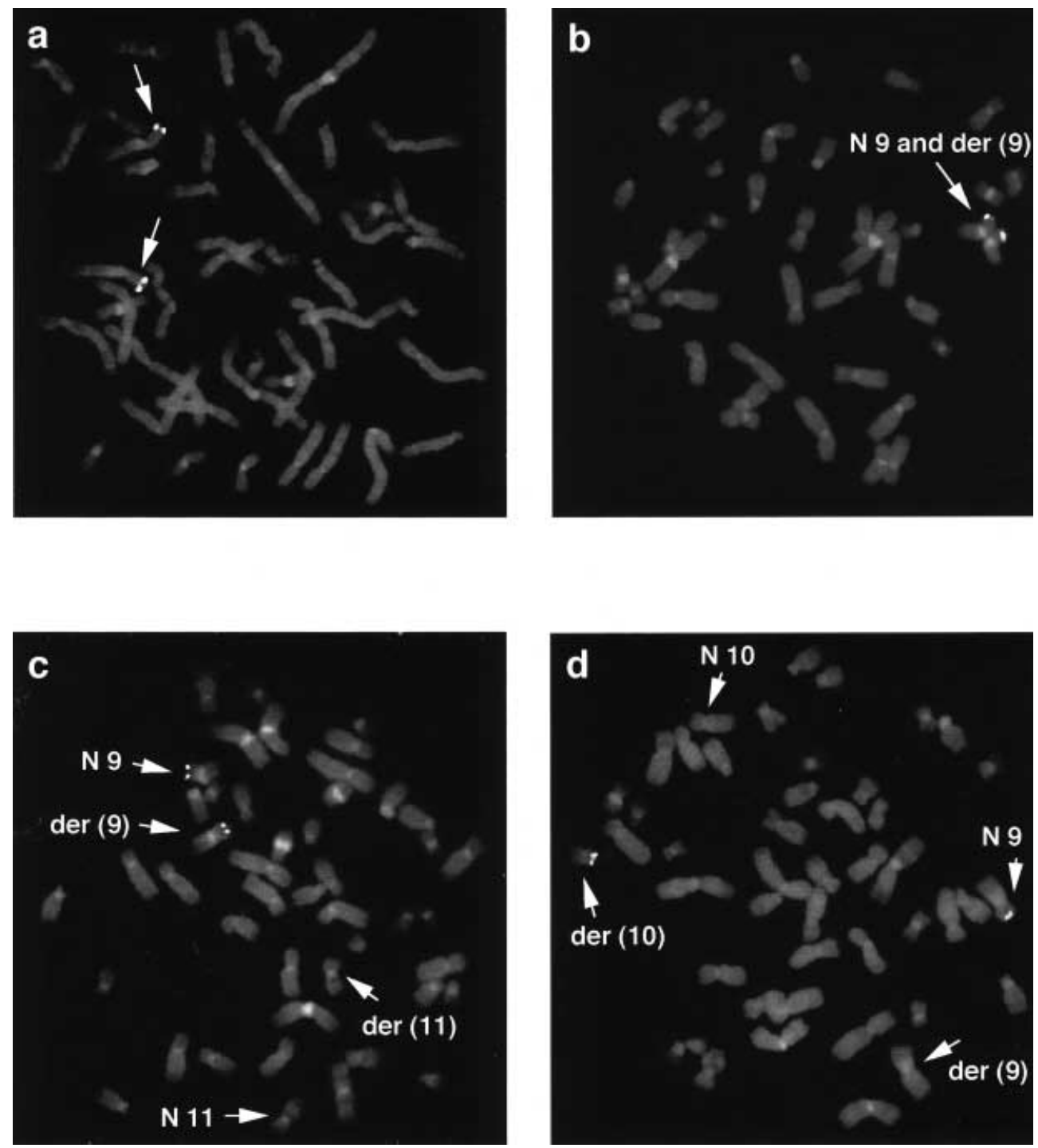

FIGURE 3. Fluorescent in situ hybridization (FISH) of metaphase chromosomes on normal and translocation breakpoints. (a) The control cell line with 46,XY karyotype shows hybridizing signals on the short arm of chromosome 9 (arrows). (b) The D1151 cell line carries the most distal balanced translocation between chr 9 (9p24-1) short arm and chr 7 (q34.1) long arm. Hybridizing signals (arrows) for RLN1 and RLN2 were found only in normal (N) chr 9 and its derivative (der 9), which still retains part of $9 \mathrm{p} 24 \cdot 1$, but not in the N7 or der 7. (c) The HW1069 cell line carries the translocation between chr 9 (p24.1) and chr 11 (q22). Hybridizing signals were found only in N9 and der 9 chromosomes which retained the 9p24.1 interval, but not in N11 and der 11. (d) The most proximal translocation is in D118 cell line, which is between chr $9(\mathrm{p} 22 \cdot 3)$ and $\operatorname{chr} 10(\mathrm{q} 11 \cdot 2)$.

Signals were detected only in N9 and der 10, which now contains a large portion of chr 9 short arm, including the 9 p22.3-9p24.1 interval.

46,XX, $\mathrm{t}(9 ; 10)(\mathrm{p} 22 \cdot 3 ; \mathrm{q} 11 \cdot 2)$ karyotype, signals were detected in those chromosomes (N9 and der 10) where the $9 \mathrm{p} 22 \cdot 3-9 \mathrm{p} 24 \cdot 1$ interval was retained or translocated, but not in those where these regions were deleted or replaced (der 9 and N10; Fig. $3 d$ ).
These data indicate that the relaxin genes are within the p22.3-p24.1 intervals of chromosome 9, and exclude them from the more distal interval 9p24-1-9pter. The combined results of the FISH and the radiation hybrid mapping show that the 
relaxin genes are clustered in the proximal portion of this interval, namely $9 \mathrm{p} 24 \cdot 1$.

\section{DISCUSSION}

The $5^{\prime}$-upstream regions of the two human relaxin $\mathrm{H} 1$ and $\mathrm{H} 2$ genes were isolated and putative regulatory elements that may affect their gene expression were identified. Gene-specific primers were designed, based on a region at their $5^{\prime}$ ends which showed a low percentage homology. These were used to map their individual chromosomal localization using a panel of 93 radiation hybrids. The same primers were also used to isolate a $\mathrm{P} 1$ clone containing the full-length relaxin $\mathrm{H} 1$ and $\mathrm{H} 2$ genes. This P1 clone was subsequently used to further confirm the chromosomal localization of these genes by breakpoint mapping using FISH analysis.

The human relaxin $\mathrm{H} 1$ and $\mathrm{H} 2$ genes share a very high degree of sequence homology, not only over the coding region $(90 \%)$ but also within their $5^{\prime}$ - and 3 '-untranslated regions (UTRs). Both relaxin genes are actively transcribed and translated in several reproductive tissues (Bryant-Greenwood \& Schwabe 1994), however, only the relaxin H2 is expressed in the corpus luteum (Hudson et al. 1984). The reason for this differential expression of the relaxin genes is unknown. Likewise, the biological significance of two relaxins in the human is an enigma, since any separate function(s) for either hormone has not been established. In an effort to provide some insights into the mechanisms involved in the differential expression of these genes, we have isolated and analyzed their $5^{\prime}$ upstream sequences. We have also determined their precise chromosomal localization in order to provide insight into their functional significance.

The detailed analysis of the $5^{\prime}$-upstream regions of the relaxin $\mathrm{H} 1$ and $\mathrm{H} 2$ genes showed that these genes share very similar features. Both genes lack a typical TATA box, but were GC-rich at their proximal regions where several $\mathrm{Sp} 1$ binding sites were noted. Moreover, three transcription initiation sites were found in both genes, however no consensus initiator sequences were found flanking these transcription cap sites. These features are very similar with TATA-less and GC-rich promoters of housekeeping genes that are constitutively expressed in low amounts (Ye et al. 1993, Bohm et al. 1995). In many of the tissues producing relaxins, the mRNA level is constantly low and they therefore appear to be constitutively expressed. However, in certain pathological conditions, such as in the preterm premature rupture of membranes, an increased level of total relaxin gene expression was observed in both the decidua and placenta (Bogic et al. 1997), implying an inducible control mechanism. The presence of cis elements such as the MREs, ZREs, and the enhancer core element in both genes suggests that the expression of these genes may be influenced by other metabolites or hormones.

An interesting feature observed in both genes are the CT-GT repeats. These repeats were positioned in the same region of both relaxin genes, but the sequences only had limited homology. These repeats may act as another transcription regulatory element (Meloni et al. 1998) and may influence their tissuespecific expression. The observed putative cis elements were found in both genes and may be involved in a common regulatory mechanism. However, the presence of a CArG box only in relaxin H1, and binding sites for AP1 and NFkB and a GRE only in relaxin $\mathrm{H} 2$, suggest that a gene-specific control mechanism may also be involved.

At the more distal region of the relaxin 5 'ends, a major decrease in the sequence homology was noted, but its significance is unknown. A similar trend was also noted in the $3^{\prime}$-UTRs of both genes (91\% overall homology) where at the distal region, a drop to 44\% homology was noted (J L GaribayTupas et al. 2000). It is possible that the DNA sequences at the distal $5^{\prime}$-upstream regions of the relaxin genes may act as gene-specific transcription regulators by providing a distinct DNA strand conformation. Since the coding and flanking regions of both relaxin genes are highly conserved, this divergence at the distal $5^{\prime}$ ends may have evolved recently to further define the control mechanisms of each gene. The significance of these regions in the transcriptional control of the relaxin $\mathrm{H} 1$ and $\mathrm{H} 2$ gene expression is currently being investigated.

The positioning of relaxin $\mathrm{H} 1$ on chromosome 9p24.1 confirms the earlier report by Bouzyk et al. (1997), and extends it to show that relaxin $\mathrm{H} 2$ is clustered within the same locus. The physical distance between these two genes and their relative orientation within chromosome 9 are still unknown, however, finding both genes within a P1 clone with a genomic insert of $80 \mathrm{~kb}$ suggests that they are relatively close together. We do not exclude the possibility that there may be other genes in-between the two relaxin genes or that they may be separated by a short intergenic region, which may even include regulatory elements shared by the two genes. In such a situation, it is likely that the relaxin genes are oriented in a head-to-head direction. Further sequencing information on the genes flanking the two relaxin genes and the putative intergenic region is needed to confirm this. 
One of the STS markers that was identified from the Whitehead Institute database to map at the same locus as the two relaxin genes was SGC34067, also known as the INSL4 gene. The chromosomal localization of this gene was earlier reported by Chassin et al. (1995) to the 9p24 locus by FISH analysis, while the Whitehead Institute maps it to a more precise position to $9 \mathrm{p} 24 \cdot 1$. The localization of these three insulin-related genes within the same chromosomal locus probably reflects their evolutionary relationship. These genes are thought to have evolved from a common insulin-like gene through a series of duplication and chromosomal translocations (McRory \& Sherwood 1997). The first duplication of this ancestral gene and the subsequent translocation event may have given rise to the modern day insulin which maps at chromosome 11p15 (Harper et al. 1981). A second duplication event followed by translocation to chromosome $9 \mathrm{p}$ may have given rise to the INSL4 and relaxin genes, which further diverged in time. While the INSL4 gene did not duplicate further, a primitive relaxin gene may have given rise to two highly homologous relaxin $\mathrm{H} 1$ and $\mathrm{H} 2$ genes. This event is likely to have been very recent, since the two relaxin genes share a very high sequence homology. Moreover, the only other primate shown to have a second relaxin gene that is actively transcribed is the chimpanzee (Evans et al. 1994). However, it is not yet known whether the chimpanzee Ch1 relaxin, which is the counterpart of relaxin H1, is functional (Evans et al. 1994). Perhaps, because of the very recent duplication of relaxins, a separate function for relaxin $\mathrm{H} 1$ has not totally evolved. Relaxin H1 may act in synergy with and augment the functions of relaxin $\mathrm{H} 2$. The identification of a single type of relaxin receptor in the decidua which is believed to mediate the biological actions of both relaxins (Garibay-Tupas et al. 1995) supports the hypothesis of synergism between relaxins $\mathrm{H} 1$ and $\mathrm{H} 2$. However, we do not exclude the possibility that relaxin $\mathrm{H} 1$ may act to regulate or modulate the activity of relaxin $\mathrm{H} 2$ by competitively binding to the same receptor.

The results presented in this study will enable us to further investigate the relative roles of relaxin $\mathrm{H} 1$ and $\mathrm{H} 2$ in the pathology of the preterm premature rupture of the membrane and preterm birth. We are now in a position to further analyze the mechanisms involved in the transcriptional control of the human relaxin genes.

\section{ACKNOWLEDGEMENTS}

We acknowledge the technical help and advice of Zoltan Szabo, Shunzhong Bao, and the helpful discussions with Dr Frederick C Greenwood. This work was supported by the Research Centers in Minority Institutions Programs of $\mathrm{NIH}$ (RR-03061).

\section{REFERENCES}

Bogic LV, Yamamoto SY, Millar LK \& Bryant-Greenwood GD 1997 Developmental regulation of the human relaxin genes in the decidua and placenta: overexpression in the preterm premature rupture of the fetal membranes. Biology of Reproduction $\mathbf{5 7}$ 908-920.

Bohm SK, Gum JR Jr, Erickson RH, Hicks JW \& Kim YS 1995 Human dipeptidyl peptidase IV gene promoter: tissue specific regulation from a TATA-less GC-rich sequence characteristic of a housekeeping gene promoter. Biochemistry Fournal 311 835-843.

Bouzyk M, Bryant SP, Evans C, Guioli S, Ford S, Schmidt K, Goodfellow PN, Povey S, Rebello M, Rousseax S \& Spurr NK 1997 Integrated radiation hybrid and yeast artificial chromosome map of chromosome 9. European Fournal of Human Genetics 5 299-307.

Bryant-Greenwood GD \& Schwabe C 1994 Human relaxins: chemistry and biology. Endocrine Review 15 5-26.

Bryant-Greenwood GD, Rutanen EM, Partanen S, Coelho TK \& Yamamoto SY 1993 Sequential appearance of relaxin, prolactin and IGFBP-1 during growth and differentiation of the human endometrium. Molecular and Cellular Endocrinology 95 23-29.

Carr-Hill RA \& Hall M 1985 The repetition of spontaneous preterm labour. British Fournal of Obstetrics and Gynaecology 92 921-928.

Chassin D, Laurent A, Janneau J-L, Berger R \& Bellet D 1995 Cloning of a new member of the insulin gene superfamily (INSL4) expressed in human placenta. Genomics 29 465-470.

Crawford RJ, Hudson P, Shine J, Niall HD, Eddy RL \& Shows TB 1984 The two human relaxin genes are on chromosome 9. EMBO Fournal 3 2341-2345.

Evans BA, Fu P \& Tregear GW 1994 Characterization of primate relaxin genes. Endocrine Fournal 2 81-86.

Garibay-Tupas JL, Maaskant RA, Greenwood FC \& BryantGreenwood GD 1995 Characteristics of the binding of ${ }^{32} \mathrm{P}$-labelled human relaxins to the human fetal membranes. Fournal of Endocrinology 145 441-448.

Garibay-Tupas JL, Bao S, Kim MT, Tashima LS \& Bryant-Greenwood GD 2000 Isolation and analysis of the 3 -untranslated regions of the human relaxin $\mathrm{H} 1$ and $\mathrm{H} 2$ genes. Fournal of Molecular Endocrinology (In Press).

Gillett GT, McConville CM, Byrd PJ, Stankovic T, Taylor AM, Hunt DM, West LF, Fox MF, Povey S \& Benham FJ 1993 Irradiation hybrids for human chromosome 11: characterization and use for generating region-specific markers in 11q14-q23. Genomics 15 332-341.

Gunnersen JM, Roche PJ, Tregear GW \& Crawford RJ 1995 Characterization of human relaxin gene regulation in the relaxin-expressing human prostate adenocarcinoma cell line LNCaP.FGC. Fournal of Molecular Endocrinology 15 153-166.

Gyapay G, Schmitt K, Fizames C, Jones H, Vega-Czarny N, Spillett D, Muselet D, Prud-Homme JF, Dib C, Auffray C, Morisette J, Weissenbach J \& Goodfellow PN 1996 A radiation hybrid map of the human genome. Human Molecular Genetics 5 339-346.

Hansell DJ, Bryant-Greenwood GD \& Greenwood FC 1991 Expression of the human relaxin $\mathrm{H} 1$ gene in the decidua, trophoblast, and prostate. Fournal of Clinical Endocrinology and Metabolism 72 899-904. 
Harper ME, Ullrich A \& Saunders GF 1981 Localization of the human insulin gene to the distal end of the short arm of chromosome 11. Proceedings of the National Academy of Sciences of the USA 78 4458-4460.

Haley J, Crawford R, Hudson P, Scanlon D, Tregear G, Shine J \& Niall HJ 1987 Porcine relaxin. Gene structure and expression. Fournal of Biological Chemistry 262 11940-11946.

Hudson P, Haley J, Cronk M, Shine J \& Niall H 1983 Structure of a genomic clone encoding biologically active human relaxin. Nature 291 127-131.

Hudson P, John M, Crawford R, Haralambidis J, Scanlon D, Gorman J, Tregear G, Shine J \& Niall H 1984 Relaxin gene expression in human ovaries and the predicted structure of a preprorelaxin by analysis of cDNA clones. EMBO Fournal 3 2333-2339.

MacLaren DC \& Clarke S 1996 Rapid mapping of genomic P1 clones: the mouse L-isoaspartyl/D-aspartyl methyltransferase gene. Genomics 35 299-307.

McRory JE \& Sherwood NM 1997 Ancient divergence of insulin and insulin-like growth factor. DNA and Cell Biology 16 939-949.

Meloni R, Albanese V, Ravassard P, Treilhou F \& Mallet J 1998 A tetranucleotide polymorphic microsatellite, located in the first intron of the tyrosine hydroxylase gene, acts as a transcription regulatory element in vitro. Human Molecular Genetics 3 423-428.

Migone A, Emanuel I, Mueller B, Daling J \& Little RE 1991 Gestational duration and birthweight in white, black, and mixed-race babies. Paediatrics Perinatology and Epidemiology 5 378-391.

Porter TF, Fraser AM, Hunter CY, Ward R \& Varner MW 1997 The risk of preterm birth across generations. Obstetrics and Gynecology 90 63-67.

Qin X, Garibay-Tupas J, Chua PK, Cachola L \& BryantGreenwood GD 1997a An autocrine/paracrine role of human decidual relaxin. I. Interstitial collagenase (MMP-1) and tissue plasminogen activator. Biology of Reproduction $\mathbf{5 6}$ $800-811$

Qin X, Chua PK, Ohira RH \& Bryant-Greenwood GD $1997 b$ An autocrine/paracrine role of human decidual relaxin. II. Stromelysin (MMP-3) and tissue inhibitor of matrix metalloproteinase-1(TIMP-1). Biology of Reproduction 56 812-820.

Roberts AK, Monzon-Bordonaba F, Van Deerlin PG, Holder J, Macones GA, Morgan MA, Strauss JF \& Parry S 1999
Association of polymorphism within the promoter of the tumor necrosis factor $\alpha$ gene with increased risk of preterm premature rupture of the fetal membranes. American fournal of Obstetrics and Gynecology 180 1297-1302.

Sakbun V, Ali SM, Greenwood FC \& Bryant-Greenwood GD 1990 Human relaxin in the amnion, chorion, decidua parietalis, basal plate and placental trophoblast by immunocytochemistry and Northern analysis. Fournal of Clinical Endocrinology and Metabolism 70 508-514.

Sanger F, Nicklen S \& Coulson AR 1977 DNA sequencing with chain-terminating inhibitors. Proceedings of the National Academy of Sciences of the USA 74 5463-5467.

Shiono PH \& Klebanoff MA 1986 Ethnic differences in preterm and very preterm delivery. American Fournal of Public Health 76 1317-1321.

Stein L, Kruglyak L, Slonim D \& Lander E 1995 'RHMAPPER', unpublished software, Whitehead Institute/MIT Center for Genome Research. Available at http://www.genome.wi.mit.edu/ftp/pub/software/rhmapper and via anonymous ftp to ftp.genome.wi.mit.edu, directory/pub/software/rhmapper

Sternberg N, Smoller D \& Braden T 1994 Three new developments in P1 cloning. Increased cloning efficiency, improved clone recovery, and a new P1 mouse library. Genetic Analysis, Techniques and Applications 11 171-180.

Szabo Z, Light E, Boyd CD \& Csiszar K 1997 The human lysyl oxidase-like gene maps between STS markers D15S215 and GHLC.GCT7C09 on chromosome 15. Human Genetics 101 198-200.

Tashima LS, Mazoujian G \& Bryant-Greenwood GD 1994 Human relaxins in normal benign and neoplastic breast tissue. Fournal of Molecular Endocrinology 12 351-364.

Walter M, Spillett D, Thomas P, Weissenbach J \& Goodfellow P 1994 A method for constructing radiation hybrid maps of whole genomes. Nature Genetics 7 22-28.

Ye K, Dinarello CA \& Clark BD 1993 Identification of the promoter region of human interleukin 1 type I receptor gene: multiple initiation sites, high $\mathrm{G}+\mathrm{C}$ content, and constitutive expression. Proceedings of the National Academy of Sciences of the USA $902295-2299$.

REVISED MANUSCRIPT RECEIVED 29 June 1999 